\title{
Frecuencia de Escherichia coli diarreogenicas aisladas de niños en un hospital pediátrico en Lima-Perú
}

\section{Frequency of diarrheogenic Escherichia coli isolated from children in a pediatric hospital in Lima-Perú}

\author{
Mirtha Roque A \\ Universidad Nacional Mayor de San Marcos, Facultad de Farmacia y Bioquímica.
}

\begin{abstract}
Resumen
La diarrea continúa siendo un problema de salud en todo el mundo especialmente en los países en vías de desarrollo donde es responsable de 1,87 millones de muertes/año en niños menores de cinco años. En el Perú se ha demostrado que Escherichia coli diarreogénicas son causa importante de diarrea en niños. Esta investigación tuvo como objetivo determinar la frecuencia de Escherichia coli enteropatógena (EPEC) en niños menores de cinco años en un hospital pediátrico de Lima Perú. Se colectaron 70 muestras de heces diarreicas de niños con síntomas clínicos de diarrea aguda del Hospital de Emergencias Pediátricas, durante los meses junio a diciembre del 2015. El aislamiento e identificación bioquímica se realizó por coprocultivos y pruebas bioquímicas convencionales, la identificación de Escherichia coli enteropatogena (EPEC) se realizó por serotificacion utilizando antisueros polivalentes y monovalentes para los antígenos somáticos $\mathrm{O}$. La determinación del antígeno somático "O" se realizó mediante la técnica de aglutinación en placa, siguiendo el procedimiento descrito por el proveedor de antisueros PROBAC DO BRAZIL. Se aislaron 50 (71,4\%) cepas de Escherichia coli diarreogénicas de las cuales $36(72 \%)$ fueron del serotipo enteropatógeno (EPEC) siendo los serogrupos más frecuentes $0119(22.2 \%), 0158(16,7 \%)$, O142 (11,1\%), O127 (8,3\%), O55 (19,4\%), O86 (8,30\%), O125 (13,9\%), el $14(28 \%)$ correspondía al serotipo productora de toxina Shiga (STEC) siendo el serogrupo mas frecuente el O111 (28\%). El 28,6\% (20/70) no evidenciaron la presencia de E.coli diarreogenicas.
\end{abstract}

Palabras clave: Escherichia coli; enteropatogena; diarrea; niños; Perú

\begin{abstract}
Diarrhea continues to be a health problem worldwide, especially in developing countries where it is responsible for 1,87 million deaths / year in children under 5 years of age. In Peru it has been shown that diarrheogenic Escherichia coli are an important cause of diarrhea in children. The objective of this research was to determine the frequency of enteropathogenic Escherichia coli (EPEC) in children under 5 years of age in a pediatric hospital in Lima, Peru. A total of 70 diarrheic stool samples were collected from children with clinical symptoms of acute diarrhea at the Pediatric Emergency Hospital, during the months of June to December 2015. Isolation and biochemical identification was performed by co-cultures and conventional biochemical tests, the identification of enteropathogenic Escherichia coli (EPEC) was performed by serotyping using polyvalent and monovalent antisera to the $\mathrm{O}$ somatic antigens. The determination of the somatic antigen "O" was performed by the plate agglutination technique, following the procedure described by the antisera supplier PROBAC DO BRAZIL. We isolated $50(71.4 \%)$ strains of diarrheic Escherichia coli of which $36(72 \%)$ were of the enteropathogenic serotype (EPEC) being the most frequent serogroups O119 (22,2\%), O158 (16,7\%), O142 (11,1\%), O127 (8,3\%), O55 (19,4\%), O86 (8,30\%), O125 (13,9\%), 14(28\%) corresponded to the Shiga toxin producing serotype (STEC), the most frequent serogroup being 0111(28\%). $28,6 \%(20 / 70)$ did not show the presence of E.coli.
\end{abstract}

Keywords: Escherichia coli enteropathogenic; diarrhea; children; Peru

\section{Correspondencia:}

Nombre: Mirtha Roque

Dirección: Jr. Puno 1002 Lima.

Email: mroquea@unmsm.edu.pe

Recibido: 04/06/2016; aceptado: 29/09/2017

Citar como:

Roque M. Frecuencia de Escherichia coli diarreogenicas aisladas de niños en un hospital pediátrico en Lima-Perú. Ciencia e Investigación 2017 20(2):23-28.

( C) Los autores. Este artículo es publicado por la Ciencia e Investigación de la Facultad de Farmacia y Bioquímica de la Universidad Nacional Mayor de San Marcos. Este es un artículo de acceso abierto, distribuido bajo los términos de la licencia Creative Commons Atribucion - No Comercia_Compartir Igual 4.0 Internacional. (http://creativecommons.org/licenses/by-nc-sa/4.0/) que permite el uso no comercial, distribución y reproducción en cualquier medio, siempre que la obra original sea debidamente citada. 


\section{INTRODUCCION}

La enfermedad diarreica aguda (EDA) constituye un problema de salud pública en el mundo, especialmente en los países en vías de desarrollo, donde son una causa de morbilidad y mortalidad en niños menores de cinco años ${ }^{1}, y$ por lo general son consecuencia de la exposición a alimentos o agua contaminados. Según estimaciones de la OMS causan la muerte de 760000 niños menores de cinco años y que ocurren mas de mil millones de episodios ${ }^{2}$.

En la semana epidemiológica, 10 del 5 al 11 de marzo del 2017, del Ministerio de salud se han notificado 250828 episodios de EDA,de este, 149497 (59,6\%) fueron notificados en mayores de 5 años, 72310 $(28,8 \%)$ en niños de 1 a 4 años y $29021(11,6 \%)$ en menores de un año. Los niños menores de un año tienen la más alta tasa de incidencia con 51,8 por 1000 , seguido de los niños de 1 a 4 años con 31,8 por 1000 . Los mayores de 5 años, tienen una tasa de incidencia de 5,2 por $1000^{3}$.

En Perú, Escherichia coli diarreogénicas son causa importante de diarrea en niños, siendo los patotipos más frecuentes E.coli enteroagregativa (EAEC), E. coli enteropatogena (EPEC), E.coli enterotoxigenica (ETEC), E. coli de Difusión adherente (DAEC) y $E$. coli productora de Shiga toxina (STEC), este último patotipo está asociado a diarrea sanguinolenta ${ }^{4,5}$ . Cada uno de los tipos patogénicos presenta diferencias a nivel de virulencia, interacción con la mucosa intestinal, síndrome clínico, epidemiología y serotipos basados en los antígenos $\mathrm{O} \mathrm{y}^{6,7}$.

Escherichia coli enteropatogénica (EPEC) tiene distribución mundial, se relaciona con brotes de diarrea en guarderías y hospitales infantiles en el verano. En 1955, el termino EPEC fue utilizado por primera vez para describir aislamientos de $E$. coli relacionados epidemiológicamente a diarrea infantil, en 1978 se demostró que EPEC era un tipo de E.coli patogénico y que tenía distintos mecanismos de patogenicidad respecto de ETEC y EIEC por lo que se iniciaron las investigaciones para identificar y caracterizar sus factores de virulencia. Desde entonces EPEC es caracterizado como una E.coli que no produce las enterotoxinas ni shigatoxinas diferenciándose así de ETEC y STEC. Sin embargo cuando coloniza el intestino produce lesiones en la mucosa intestinal de humanos y animales que conducen a la diarrea ${ }^{8}$.

Escherichia coli (STEC) productor de toxina Shiga ha surgido como un grupo de patógenos transmitidos por los alimentos que pueden causar graves enfermedades humanas,tales como el síndrome urémico hemolítico (SHU).Tradicionalmente la clasificación de Escherichia coli se realiza según el esquema modificado propuesto por Kauffmann en 1994. De acuerdo con este esquema modificado las cepas de E.coli son serotipadas principalmente por la determinación del tipo de antígeno somático "O", el tipo de antígeno flagelar " $\mathrm{H}$ ", y el antígeno capsular " $\mathrm{K}$ ". El antígeno "O" es el responsable del serogrupo; la determinación del antígeno somático y flagelar $(\mathrm{O}: \mathrm{H})$ indica el serotipo, el cual en ocasiones se asocia con cuadros clínicos en particular. Actualmente se tiene 176 antígenos somáticos $(\mathrm{O}), 112$ flagelares $(\mathrm{H})$ y 60 capsulares $(\mathrm{K})^{8}$. El antígeno $\mathrm{O}$ es un polisacárido termoestable post calentamiento a $121^{\circ} \mathrm{C}$ por 2 horas, que forma parte del lipopolisacarido (LPS) presente en la membrana externa de la pared celular?

La clasificación serológica por la estructura antigénica es muy útil en los estudios epidemiológicos y de patogénesis de Escherichia coli, facilitando la diferenciación entre cepas virulentas e inocuas sin embargo tiene una sensibilidad y especificidad limitada por ser un procedimiento tedioso, caro, que requiere muchos antisueros y es realizado solo con fines epidemiológicos o de investigación en laboratorios de referencia. Por estas razón, la clasificación de E. Coli a patógenas se ha centrado en la identificación de los factores de virulencia los cuales incluyen ensayos fenotípicos in vitro que se correlacionan con rasgos específicos de la virulencia y la detección de los genes que codifican los factores de virulencia ${ }^{8}$. Los objetivos de este trabajo fueron, aislar e identificar Escherichia coli diarreogénicas a partir de muestras diarreicas de niños menores de 5 años en un hospital pediátrico de Lima Perú; así como serotipificar por pruebas serológicas los aislamiento para establecer la frecuencia de serogrupos basados en los antígenos somáticos $\mathrm{O}$.

\section{MATERIAL Y MÉTODOS}

Población y muestra. Durante los meses de junio-diciembre del 2015, se recolectaron 70 muestras de heces provenientes de niños menores de 5 años que fueron llevados al Hospital de Emergencia Pediátricas de Lima, por presentar cuadro diarreico agudo y persistente. Las muestras fueron colectadas por hisopado rectal que se mantuvo en medio de transporte de Cary Blair hasta su procesamiento en el laboratorio. Aislamiento e identificación. Se realizó la siembra de las muestras de heces por extensión y agotamiento en placas de los siguientes medios de cultivo: Agar Mac Conkey y agar Mac Conkey Sorbitol, incubándose a $37{ }^{\circ} \mathrm{C}$ por 24 horas. Las colonias con las características morfológicas típicas o sospechosas de Escherichia coli fueron aisladas en número de cinco por cada muestra analizada e identificadas con las pruebas bioquímicas convencionales. ${ }^{9}$

Las muestras cuyas cinco colonias se identificaron como Escherichia coli, fueron conservadas en agar tripticasa soya para las posteriores pruebas serológi- 
cas. Se determinó los serogrupos de Escherichia coli diarreogénicas mediante pruebas serológicas con antígenos somáticos $\mathrm{O}$ polivalentes $\mathrm{A}, \mathrm{B}$ y $\mathrm{C}$ en cuya composición se tienen los antígenos somáticos para el serogrupo y antígenos $\mathrm{O}$ monovalentes marca (PROBAC ()$^{10,11}$,según (Tabla 1).

Tabla 1. Antisueros polivalentes y monovalentes utilizados en la serotipificacion de cepas de Escherichia coli diarreogenicas.

\begin{tabular}{ll}
\hline Sueros polivalentes & Sueros monovalentes \\
\hline & $\mathrm{O} 26, \mathrm{O} 55, \mathrm{O} 111, \mathrm{O} 119$ \\
$\mathrm{~A}(\mathrm{O} 26, \mathrm{O} 55, \mathrm{O} 111, \mathrm{O} 119)$ & $\mathrm{O} 114, \mathrm{O} 125, \mathrm{O} 142, \mathrm{O} 158$ \\
$\mathrm{~B}(\mathrm{O} 114, \mathrm{O} 125, \mathrm{O} 142, \mathrm{O} 158)$ & $\mathrm{O} 86, \mathrm{O} 126, \mathrm{O} 127, \mathrm{O} 128$ \\
$\mathrm{C}(\mathrm{O} 86, \mathrm{O} 126, \mathrm{O} 127, \mathrm{O} 128)$ & $\mathrm{O} 145, \mathrm{O} 29, \mathrm{O} 45, \mathrm{O} 103$ \\
& $\mathrm{O} 136, \mathrm{O} 167, \mathrm{O} 124$ \\
\hline
\end{tabular}

A partir de cepas de Escherichia coli diarreogénicas aisladas en agar Mac Conkey se sembró 3 colonias en caldo infusión cerebro corazón (BHI) en tubos conteniendo $5 \mathrm{~mL}$ de medio e incubo a $37^{\circ} \mathrm{C} \pm 1{ }^{\circ} \mathrm{C}$ durante 24 horas. Transcurrido el tiempo de incubación se procedió al hervido de los caldos inoculados en un baño térmico a $100{ }^{\circ} \mathrm{C}$ durante una hora. Seguidamente se dejó enfriar para que las células lisadas sedimenten y no interfieran con la reacción de aglutinación. Luego se procedió a colocar en una microplaca $25 \mu \mathrm{L}$ de la suspensión hervida de los aislados, 12 pocillos por cada cepa. En cada pocillo se añadió $25 \mu \mathrm{L}$ de cada uno de los sueros polivalentes y monovalentes. Se incubó la microplaca a $50-52 \pm 1^{\circ} \mathrm{C}$ en atmósfera húmeda durante $22 \pm 2$ horas. Como control negativo se añadió en otro pocillo $25 \mu \mathrm{L}$ de la suspensión bacteriana junto con $25 \mu \mathrm{L}$ de solución salina estéril. La reacción positiva de aglutinación se observo por la formación de una malla en el pocillo y la reacción negativa por la sedimentación de las células lisadas

\section{RESULTADOS}

Luego de la recolección de muestras se determinó la distribución de pacientes por edad.(Tabla 2).

Tabla 2. Distribución de pacientes con diarrea aguda según edad

\begin{tabular}{ccc}
\hline \multirow{2}{*}{$\begin{array}{c}\text { Grupo Etario } \\
\text { (años) }\end{array}$} & Hospital Emergencias Pediátricas \\
\cline { 2 - 3 } Menor de 1 & 20 & $\%$ \\
1 & 20 & 28,6 \\
2 & 5 & 28,6 \\
3 & 5 & 7,1 \\
4 & 5 & 7,1 \\
5 & 5 & 7,1 \\
Mayor de 5 & 10 & 7,1 \\
Total & 70 & 14,4 \\
& & 100,0 \\
\hline
\end{tabular}

Luego del aislamiento en medios de cultivo como agar Mac Conkey y Mac Conkey sorbitol y la corres- pondiente identificación bioquímica se estableció los serogrupos por serotipificación utilizando antisueros polivalente y monovalentes somáticos que estaban constituidos por el antígeno somatico O (Tabla 3).

\begin{tabular}{c|c|c}
\multicolumn{3}{c}{ Tabla 3. Serogrupos de Escherichia coli enteropatógena } \\
\hline Serotipo EPEC & Frecuencia & Porcentaje (\%) \\
\hline O55 & 7 & 19,4 \\
O86 & 3 & 8,3 \\
O119 & 8 & 22,2 \\
O125 & 5 & 13,9 \\
O127 & 3 & 8,3 \\
O142 & 4 & 11,1 \\
O158 & 6 & 16,7 \\
Total & 36 & 100,0 \\
\hline
\end{tabular}

\section{DISCUSIÓN}

Las enfermedades diarreicas siguen representando más de 2 millones de muertes al año y se asocia con el desarrollo deficiente en los países con recursos limitados.

En este estudio de un total de 70 muestras diarreicas recolectadas y analizadas según el protocolo propuesto por Mindy ${ }^{10,11}$ encontramos en 50 muestras Escherichia coli diarreogénicas y las otras muestras correspondían a Escherichia coli comensal no patógena lo que indicaría en estos casos que el agente causal de la diarrea es rotavirus u otro agente patogeno.

Se aislaron $50(71,4 \%)$ cepas de Escherichia coli diarreogénicas de las cuales 36 (72\%) fueron E.coli enteropatógeno (EPEC) y los serogrupos más frecuentes O119 (22,2\%), O158 (16,7\%), O142 (11,1\%), O127 $(8,3 \%)$, O55 (19,4\%), O86 (8,30\%), O125 (13,9\%), 14 ( $28 \%)$ correspondían al serotipo productora de toxina Shiga y el serogrupo O111. El 28,6\% (20/70) no evidenciaron la presencia de E.coli diarreogenicas.

Los diferentes patotipos de las E. coli diarreogenicas han sido evaluados en estudios en poblaciones pediátricas en el Perú entre 1987 al 2009 por Ochoa ${ }^{5}$, usando una variedad de métodos de diagnóstico, en un primer informe sin utilizar métodos moleculares se reportó que la prevalencia de EPEC en niños varia de 1 a 28\%. Entre los años 2005 a 2010 Ochoa T, Mercado E. y col ${ }^{16}$ analizaron 8003 muestras para la determinación de la prevalencia de E. coli diarreogenicas en el Perú, se utilizaron cepas de E.coli previamente aisladas de 3,284 pacientes pediátricos de ocho estudios previos, la metodología analítica empleada fue PCR en tiempo real, obteniéndose que, las EPEC atípicas $(54 / 74,73 \%)$ fueron el tipo más frecuente.

Entre los enteropatógenos asociados a diarreas, las bacterias se encuentran entre los principales agentes 
causales en casi todos los países del mundo. Así en Argentina, Quiroga ${ }^{12}$ reporta en 510 muestras de heces que el $28,8 \%$ correspondían a Escherichia coli EPEC. Vizcaya ${ }^{13}$ en un estudio en Caracas determinó la frecuencia de Escherichia coli enteropatógena en un 13,5 \%. En otros países como Costa Rica, Herrera $^{14}$ determina que el $8,4 \%$ correspondían a EPEC, Henríquez ${ }^{15}$ en un Hospital de Concepción en Chile identifica Escherichia coli EPEC en un 10\% en pacientes con diarrea de 1 a 24 meses . En Paraguay, Weiler ${ }^{17}$ en 180 muestras entre 2012 y 2015 reporta una frecuencia de 61(34\%) ETEC, 40(22\%) EAEC, 41(23\%) EPEC, 27(15\%) entre los principales serotipos.

La serotipificación se realizó con fines de investigacion para determinar el serogrupo más frecuente a través del uso de antisueros polivalentes y monovalentes evidenciando el predominio del O119, O158, O142, O55 y O86 hallazgos similares a lo reportado en el estudio realizado por Varela G,Jasinski C y $\operatorname{col}^{17}$ en Uruguay en 95 niños con EDA menores de 5 años, mediante la serotipificacion,biotipificacion y tipificación de genes para la detección de EPEC, se reportaron 26 cepas EPEC, 15 correspondientes a cepas típicas y 11 a cultivos atípicos, la distribución de serogrupos por la identificación del antígeno somático $\mathrm{O}$ reportan a los serogrupos más frecuentes a O55 (8 cepas), O119 (4 cepas), O142 (2 cepas), O111 (2 cepas) y O26 (2 cepas). Asi mismo lo menciona Ambrosius ${ }^{18}$ de México en 70 casos de Infecciones enterales por diferentes cepas de Escherichia coli donde se reportó que el $67 \%$ de los casos correspondían a los serotipos O119, O111, O86, lo cual indica que estos serotipos se encuentra ampliamente distribuido en diferentes continentes y se debe monitorizar y asociar a cuadros graves de diarrea.

Los resultados obtenidos nos demuestran que Escherichia coli enteropatógena (EPEC) es el agente etiológico de diarrea en niños en Lima y la frecuencia varia de estudio en estudio según la edad del paciente y los factores inherentes al agente infeccioso. Dentro de las limitaciones del estudio encontramos que los cultivos de Escherichia coli en los medios de cultivo Mac Conkey y Mac Conkey sorbitol no permiten discriminar las cepas patógenas de las comensales por lo que sería más conveniente determinar los factores de virulencia por biología molecular y correlacionar su presencia con la serotipia.

En conclusión la frecuencia de Escherichia coli EPEC es similar a lo reportado en otros países de América Latina, siendo los más afectados los niños menores de 1 año (Tablas 2 y 3 ). El serogrupo más frecuente fue O119 (22,2\%) en 2015(Tabla 3).

\section{AGRADECIMIENTOS}

A los médicos del Hospital de Emergencias Pediátricas por el apoyo en la realización del presente trabajo.

\section{REFERENCIAS BIBLIOGRÁFICAS}

1. Boschi-Pinto C, Velebit L, Shibuya K. Estimating child mortality due to diarrhoea in developing countries. Bull World Health Organ. 2008; 86(9):710-17.

2. OMS [Internet] Enfermedades Diarreicas. Nota Descriptiva [citado en mayo 2017]. Recuperado a partir de: http://www.who. int/mediacentre/factsheets/fs330/es/

3. Ordoñez, L. Situación Epidemiológica de las Enfermedades Diarreicas Agudas (EDA) en el Perú. Boletín Epidemiológico, 2017; 26(11): 312-15.

4. Ochoa TJ, Contreras C, Mosquito S. Alcances sobre la situación epidemiológica de las $E$. coli diarreogenicas aisladas en niños Peruanos. Can Pediatr. 2010; 34(3):133-38.

5. Arias I, Cáceres O, Figueroa M. Huguet J, Carmiña M. Escherichia coli enteroagregativa en niños con diarrea de un hospital de Lima. Rev Perú Med Exp. Salud Pública. 2004; 21(3):176-8.

6. Rodríguez G, Ángeles M. Principales características y diagnóstico de los grupos patógenos de Escherichia coli Salud Pública México 2002 Septiembre-Octubre. 44(5): 464-75.

7. Nataro JP, Kaper JB. Diarrhoegenic Escherichia coli .Clin Microbiol Rev.1998; 11(1): 142-201.

8. Lluque A, Mercado E, Riveros M, Alvarado L, Carlos E, Colichon $A$, et al. Comparison of enteropathogenic Escherichia coli (EPEC) diagnosis by serology and by polymerase chain reaction (PCR). Rev Gastroenterol Peru. 2010;30(2):121-5.

9. Manual de Procedimientos. Diagnóstico de Escherichia coli productor de Toxina Shiga. Instituto Nacional de Enfermedades Infecciosas. ANLIS. "Dr. Carlos Malbrán". Buenos Aires .Argentina; 2003:1-9.

10. Mindy Perilla, Ajillo Gloria. Manual de Laboratorio para la Identificación y Prueba de Susceptibilidad a los Antimicrobianos de patógenos bacterianos de importancia para la Salud Pública . WHO/CDS/CSR/RMD/.2003;6: 111-123

11. Quiroga M, Oviedo P, Chinen I. Asymptomatic Infections by Diarrhoegenic Escherichia coli in children from Misiones, Argentina, during the first twenty months of their lives. Rev Inst de Med Trop de Sao Paulo. 2000 Jan-Feb; 42(1): 9-15.

12. Vizcaya E, Flores A. Origen bacteriano de la enfermedad diarreica aguda en Mérida Venezuela. Rev Cub Med Trop 1999. 51(1): 14-19.

13. Herrera M, Bolaños L, Rivera H. Incidencia de Clostridium difficile y otros agentes en pacientes con diarrea. Rev Costarric Cienc Med. 1986 ; 7(3):287-291.

14. Henríquez M, Venegas G, Soto G. Etiología Bacteriana de la Diarrea Aguda del lactante en Otoño e Invierno. Rev Chil de Ped 1985; 56(6): 450- 453.

15. Ochoa, T. J., Mercado, E. H., Durand, D., Rivera, F. P., Mosquito, S., \& Contreras, C. Frecuencia y Patotipos de Escherichia coli Diarreogénica en niños peruanos con y sin diarrea. Rev Perú Med Exp Sal Púb 2011; 28(1): 13-20. 
16. Varela G, Jasisnki C. Escherichia coli enteropatógeno clásico (EPEC) asociado a casos de diarrea en niños usuarios del Hospital Pereira Rossell. Aspectos clínicos y características de las cepas involucradas. Rev Med Urug 2007;23:153-63

17. Weiler N, Orrego M, Alvarez M, Huber C. Detección molecular de Escherichia coli diarreogenica en pacientes pediátricos con síndrome diarreico agudo en Paraguay. Mem Inst Investig Cien Salud. 2017;15(1):16-21

18. Ambrosius D, Kurt, Salazar F. M. Patología de las Infecciones Intestinales por Escherichia coli enteropatógena. Bol Méd Hosp Infant Méx. 1987 Febrero; 44: 97-101. 
